\title{
Article \\ A Crucial Role of Mitochondrial Dynamics in Dehydration Resistance in Saccharomyces cerevisiae
}

\author{
Chang-Lin Chen ${ }^{1} \oplus$, Ying-Chieh Chen ${ }^{1}$, Wei-Ling Huang ${ }^{1}$, Steven Lin ${ }^{2}{ }^{\oplus}$, Rimantas Daugelavičius ${ }^{3}{ }^{\oplus}$, \\ Alexander Rapoport ${ }^{4} \mathbb{D}$ and Chuang-Rung Chang ${ }^{1, * \mathbb{D}}$ \\ 1 Institute of Biotechnology, National Tsing Hua University, 101, Section 2, Kuang-Fu Road, \\ Hsinchu City 300044, Taiwan; jasonh456@gmail.com (C.-L.C.); b09160187196418b@hotmail.com (Y.-C.C.); \\ weiling850303@gmail.com (W.-L.H.) \\ 2 Institute of Biological Chemistry, Academia Sinica, 128, Section 2, Academia Road, Nankang, \\ Taipei 115201, Taiwan; stevenlin@gate.sinica.edu.tw \\ 3 Department of Biochemistry, Faculty of Natural Science, Vytautas Magnus University, Vileikos 8, \\ 44404 Kaunas, Lithuania; rimantas.daugelavicius@vdu.lt \\ 4 Institute of Microbiology and Biotechnology, University of Latvia, Jelgavas Str., 1-537, LV-1004 Riga, Latvia; \\ rapoport@mail.eunet.lv \\ * Correspondence: crchang@life.nthu.edu.tw; Tel.: +886-35-742-776
}

Citation: Chen, C.-L.; Chen, Y.-C.; Huang, W.-L.; Lin, S.; Daugelavičius, R.; Rapoport, A.; Chang, C.-R. A Crucial Role of Mitochondrial Dynamics in Dehydration Resistance in Saccharomyces cerevisiae. Int. J. Mol. Sci. 2021, 22, 4607. https://doi.org/ $10.3390 /$ ijms 22094607

Academic Editor: Sergio Giannattasio

Received: 26 February 2021

Accepted: 26 April 2021

Published: 27 April 2021

Publisher's Note: MDPI stays neutral with regard to jurisdictional claims in published maps and institutional affiliations.

Copyright: (c) 2021 by the authors. Licensee MDPI, Basel, Switzerland. This article is an open access article distributed under the terms and conditions of the Creative Commons Attribution (CC BY) license (https:/ / creativecommons.org/licenses/by/ $4.0 /)$.

\begin{abstract}
Mitochondria are dynamic organelles as they continuously undergo fission and fusion These dynamic processes conduct not only mitochondrial network morphology but also activity regulation and quality control. Saccharomyces cerevisiae has a remarkable capacity to resist stress from dehydration/rehydration. Although mitochondria are noted for their role in desiccation tolerance, the mechanisms underlying these processes remains obscure. Here, we report that yeast cells that went through stationary growth phase have a better survival rate after dehydration/rehydration. Dynamic defective yeast cells with reduced mitochondrial genome cannot maintain the mitochondrial activity and survival rate of wild type cells. Our results demonstrate that yeast cells balance mitochondrial fusion and fission according to growth conditions, and the ability to adjust dynamic behavior aids the dehydration resistance by preserving mitochondria.
\end{abstract}

Keywords: mitochondria; dehydration; dynamics; yeast

\section{Introduction}

Saccharomyces cerevisiae is an anhydrobiotic fungus that can survive under a longterm desiccated condition. Yeast cells can resist mechanical, oxidative, osmotic, or other stressful constraints under a desiccated condition [1,2]. Since preserving yeast cells in a dry condition is critical for winery, food industry, and medical applications [3], it is valuable for us to understand the underlying mechanisms of how yeast cells overcome a desiccation condition.

Trehalose, sugar alcohol and hydrophilin (Late embryogenesis abundant protein (LEA) in plants) can be used to substitute water molecules to maintain structure and activity of cell components like lipid bilayer, proteins, and nucleic acids in yeast cells during dehydration [4-10]. Additionally, cellular organelle maintenance and inheritance are involved in desiccation [11]. It is known that during dehydration and rehydration, cells with a better capacity to preserve functional organelles and membranes have a better chance to survive [12].

Mitochondria are essential organelles responsible for energy production, and are also involved in calcium homeostasis, fatty acid oxidation, lipid synthesis, and many other critical cellular metabolic reactions [13-16]. Previous studies have indicated that mitochondria integrity is closely correlated to desiccation tolerance [17-19]. Mitochondria are dynamic organelles [20]. These organelles are not static; instead, they continue to go through fusion, fission, and transport [21]. The dynamic processes are important for mitochondria quality 
control [22]. Damaged mitochondria are eliminated through sophistically balancing between these dynamic processes. In yeast cells, DNM1 encodes a dynamin-related GTPase that performs mitochondrial fission [23]. Dnm1 is recruited by Fis1, a Dnm1 receptor, to mitochondrial tubules and assembles as ring structure to constrict and cleave both outer and inner membrane of mitochondria. On the other hand, FZO1 encodes a transmembrane GTPase on the mitochondrial outer membrane for collaborating with Mgm1 and Ugo1 to fuse outer and inner mitochondrial membranes [24]. Several signaling pathways have been implicated in the regulation of mitochondrial dynamics, such as post-translational modifications of conventional fusion/fission factor and ER/mitochondria contacts [25-27].

Although mitochondrial integrity is critical for desiccation tolerance, how cells maintain mitochondria during dehydration/rehydration remains unclear. To address this issue, we focused on the contributions of dynamic factors in different growth conditions for dehydration resistance. Our results demonstrated that disrupting mitochondrial dynamics in stationary phase severely hampered the capability of cells to deal with dehydration/rehydration stress. A well-maintained dynamic balance of fusion and fission supports mitochondrial genome integrity and functions that help in dehydration resistance.

\section{Results}

\subsection{Stationary Growth Aids Resistance to Dehydration}

We followed the dehydration and rehydration protocol to create anhydrobiosis state of cells as shown in Figure 1a to examine the desiccation tolerance of yeast cells [28]. Anhydrobiosis is a unique dormant state of cells under a highly dehydrated condition. The desiccated cells contained less than $10 \%$ water compared to cells before dehydration. To elucidate whether growth condition has an impact on desiccation tolerance, exponential and stationary phase cell samples were collected and dehydrated as shown in Figure 1a,b. We used spot assay with serially diluted cells to compare the desiccation survival rate of different samples after rehydration. Whether cells enter diauxic shift or not, samples taken from stationary growth phase have a much better survival rate after rehydration than those without (Figure 1c). These results demonstrated that pre-dehydration growth condition would affect survival rate and desiccation tolerance.

(a)

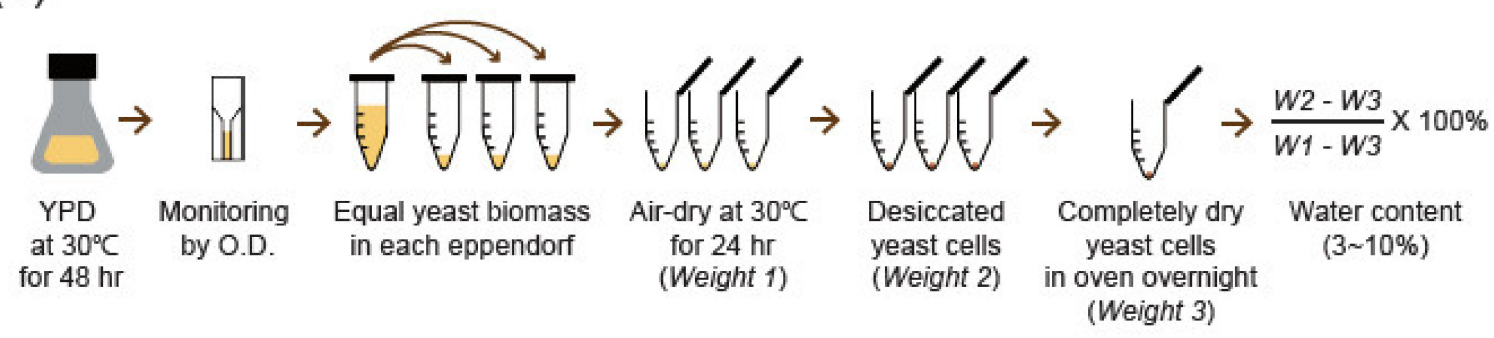

(b)

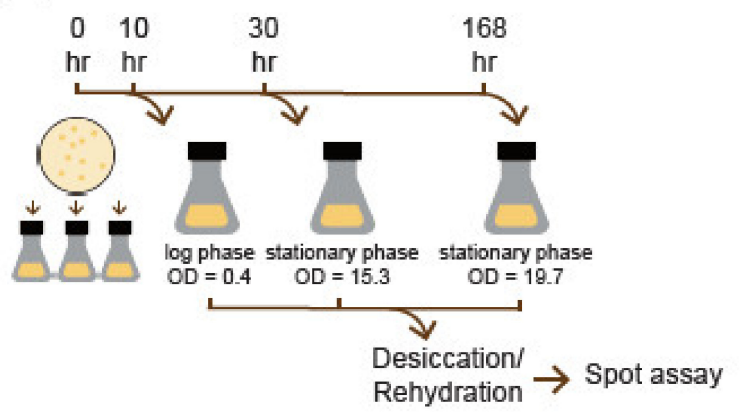

(c)

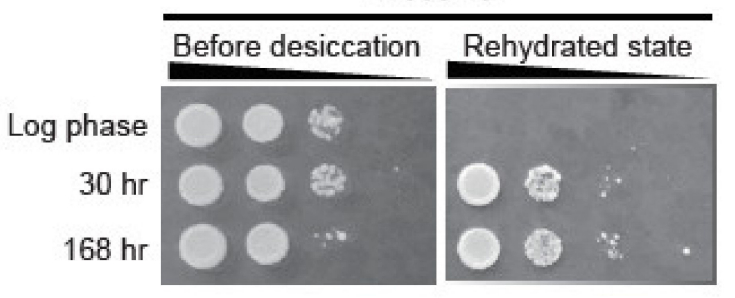

Figure 1. Yeast cells are more resistant to dehydration after stationary growth phase. (a) Dehydration procedure for yeast cells and the calculation of remaining water of the dehydrated cells. (b) Yeast cell samples were taken from log and stationary growth phases as depicted for dehydration/rehydration. (c) Resistance to dehydration is assayed by viability spotting assay. 


\subsection{Mitochondrial Network Exhibited Fragmented Morphology in Stationary Phase}

To clarify whether mitochondrial dynamics contribute to dehydration resistance for cells that went through stationary growth, we targeted GFP to mitochondria for examining the organellar network morphology. Mitochondrial network morphology is determined by the dynamic balance. Sample cells were taken from log and stationary growth phases. We found that the majority of cells in log phase contain the tubular form of mitochondrial network. Approximately $73 \%$ of cells on average from the stationary phase were found to have fragmented mitochondria (Figure 2). The results led us to speculate a regulatory mechanism to tune the balance of mitochondrial dynamics during stationary phase growth Dynamic fusion and fission are known to maintain active mitochondria [29]. This finding led us to suspect that being able to adjust the dynamic balance may contribute to maintenance of mitochondria under stress of dehydration/rehydration processes.
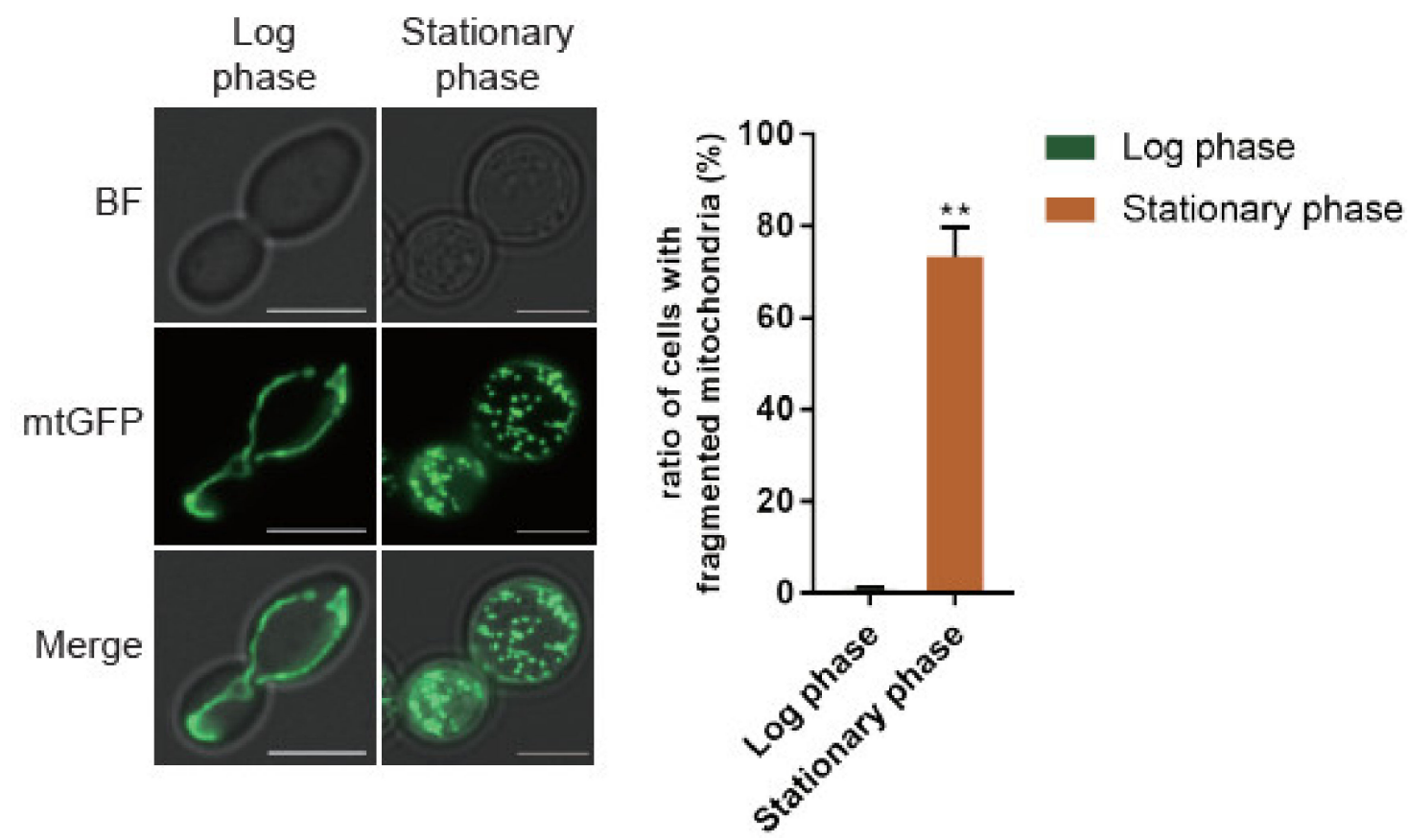

Figure 2. The balance of mitochondrial dynamics shifts toward fission in stationary phase. Representative mitochondrial network morphology in both log and stationary growth phases. Three independent trials of cells were collected, and the difference of the percentage of cells containing fragmented mitochondria were assayed by paired student $t$ test. ${ }^{* *}: p$ value $<0.01$.

\subsection{Disrupted Mitochondrial Dynamics Impairs Resistance to Dehydration}

Mitochondria fission in yeast cells is mediated by Dnm1. On the other hand, fusion is by Fzo1. We constructed dynamic defect strains $\Delta d n m 1, \Delta f z o 1$ and $\Delta d n m 1 \Delta f z o 1$ double deletion strains to elucidate the roles of mitochondrial dynamics in the dehydration resistance during the stationary growth phase. $\Delta d n m 1$ cells contained a hyperfused mitochondrial network, while $\Delta f z 01$ cells harbored fragmented mitochondria. $\Delta d n m 1 \Delta f z o 1$ cells possess the tubular form of mitochondria (Figure 3a). These results confirmed that deletion of conventional fusion/fission factors did disrupt mitochondrial dynamics. A noticeable result is that double deletion strain $\Delta d n m 1 \Delta f z o 1$ possessed similar mitochondria as the wild type cells. To examine whether the change of dynamic balance in the stationary phase contributed to desiccation tolerance, we examined the survival rate of $\Delta d n m 1, \Delta f z 01$ and $\Delta d n m 1 \Delta f z o 1$ cells that went through stationary phase growth and dehydration/rehydration processes. Based on the semi-quantitative colony numbers of the serial dilution spotting assay, we found that the $\Delta d n m 1$ strain had about ten folds fewer cells after dehydration compared to the wild type strain. $\Delta f z o 1$ strain had the worst survival rate among mutant strains. Surprisingly, the double deletion strain $\Delta d n m 1 \Delta f z o 1$ had a similar survival rate 
as the wild type cells (Figure 3b and Supplemental Figure S1). The cell survival results after dehydration/rehydration supported the hypothesis that mitochondrial dynamics are critical for desiccation tolerance.
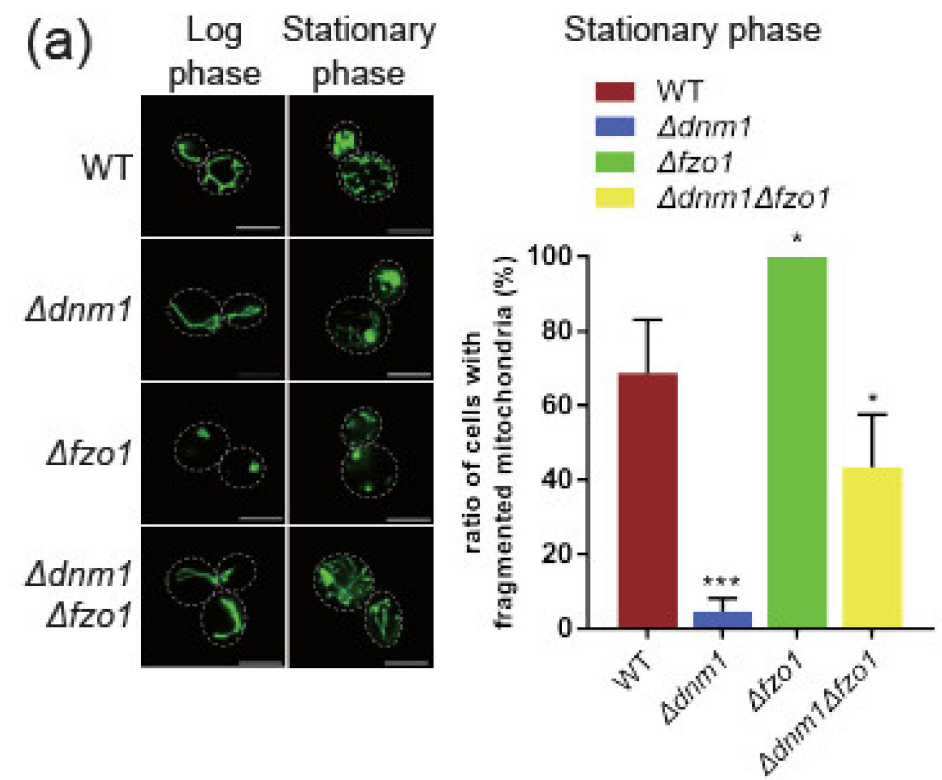

(b)

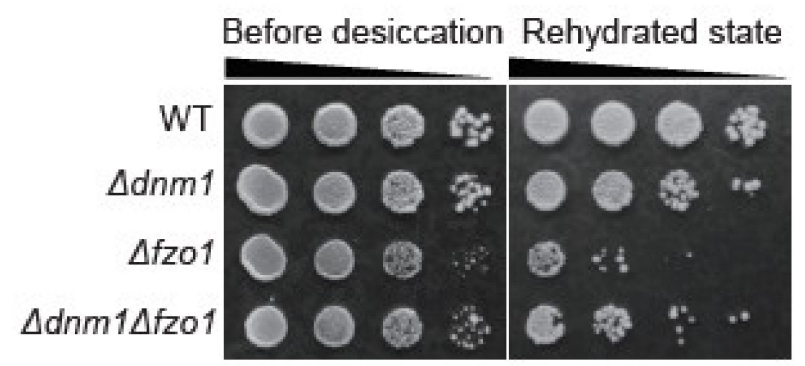

Figure 3. Mitochondrial dynamics defects attenuate dehydration resistance. Deletion of mitochondrial fusion Fzo1 and fission Dnm1 factors reduce cell survival after dehydration/rehydration. (a) Representative mitochondria network morphology of wild type and dynamic defect strains from samples taken from the stationary phase. Quantitative results are from three individual trials of experiments; at least 100 cells were examined in each trial. One-way ANOVA was used for statistical analysis. (b) Spot assay results for cell viability before and after dehydration. A ten-foldserial dilution of cells were spot on the YPD plates. *: $p$ value $<0.1{ }^{* * *}: p$ value $<0.001$.

\subsection{Dynamic Processes Mediated mtDNA Maintenance Is Correlated with Dehydration Resistance}

Alterations of mitochondrial dynamics resulting in a loss of mtDNA and/or aberrancies in mt-nucleoid morphology have been reported in both mammalian and yeast cells [30-32]. To characterize the role of mtDNA maintenance in desiccation tolerance, we examined the mtDNA copy numbers of wild type, $\Delta d n m 1, \Delta f z o 1$ and $\Delta d n m 1 \Delta f z o 1$ strains in both log phase and stationary phase cells. Comparing the quantitative PCR results of mtDNA, we found $\Delta d n m 1, \Delta f z o 1$ and $\Delta d n m 1 \Delta f z o 1$ strains possessing less mtDNA than wild type cells in both log and stationary growth conditions (Figure 4). Especially, mtDNA copy number was severely reduced in the $\Delta f z o 1$ strain. In addition, cell samples taken from stationary growth phase have at least 2 folds higher mtDNA copy number than those from the log phase. These results indicated that maintaining the ability of mitochondria to fuse and divide helps to maintain mitochondrial genome. Stationary phase growth was apparently linked to higher mtDNA copy number. Higher mtDNA copy number equated with better survival rate after dehydration/rehydration as shown in Figure $3 b$.

\subsection{Disrupted Dynamic Processes Change Mitochondrial Activity}

The mitochondria genome encodes critical components for respiration complexes. To clarify the mitochondria activity of wild type and dynamic defect cells in both log and stationary growth phases, we applied the Oroboros Oxygraph $2 \mathrm{~K}^{\circledR}$ high-resolution respirometer to record the oxygen consumption rate. Except for monitoring the routine respiration, a coupling control protocol (CCP) was used to challenge different oxidative phosphorylation complexes for evaluating respiration capacity. Coupling control protocol added oxidative phosphorylation inhibitors, triethyltin bromide (TET), Carbonyl cyanide4-(trifluoromethoxy)phenylhydrazone (FCCP) and antimycin (AntA) sequentially while assaying oxygen consumption rate [33,34]. We found that cells at stationary phase growth 
have lower routine respiration (Figure 5a). Strains with mitochondrial dynamics factor deletion have even lower routine respiration rate than normal. Despite the effect on routine respiration, the spare respiration capacity did not exhibit significant difference between log and stationary phase cells (Figure 5b).

\section{S rRNA / SCR1}

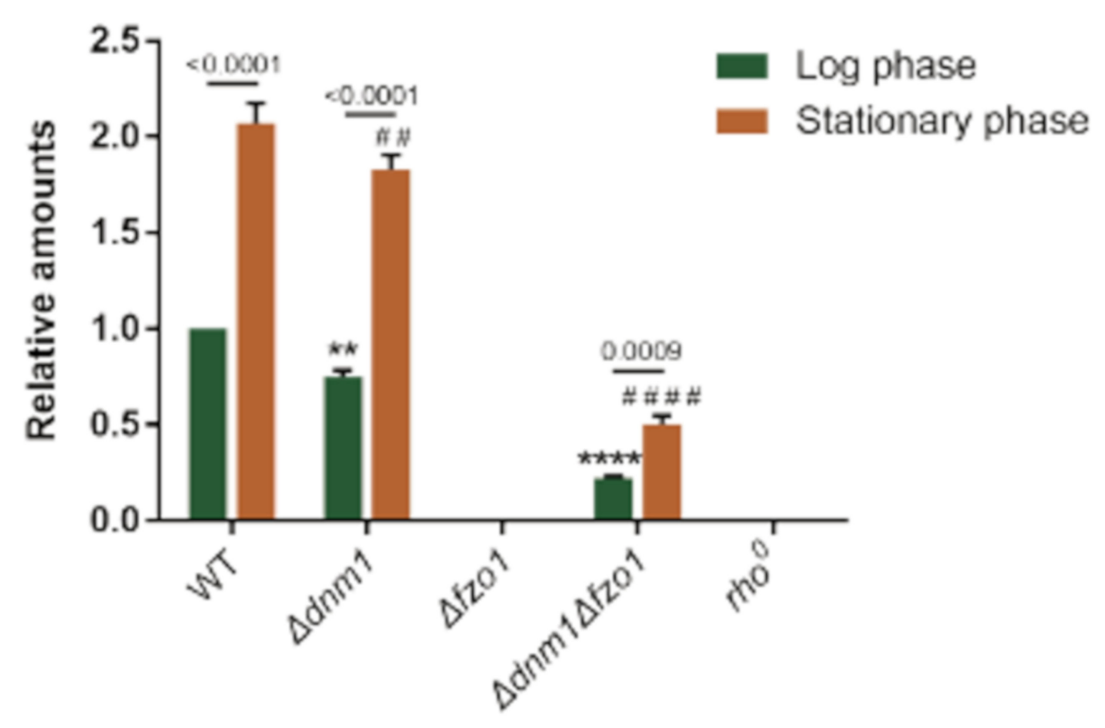

Figure 4. Dehydration resistance is proportion to mtDNA copy number. Quantitative PCR was used to examine the ratio of mitochondrial (21S rRNA) and nuclear genome (SCR1) copy number. All results were normalized to log growth phase wild type strain. The two-way ANOVA multiple comparison was used for statistics analysis. ${ }^{* *} /{ }^{\# \#}: p$ value $<0.01 ;{ }^{* * * *} /{ }^{\# \# \#}$ : $p$ value $<0.0001$.

(a)

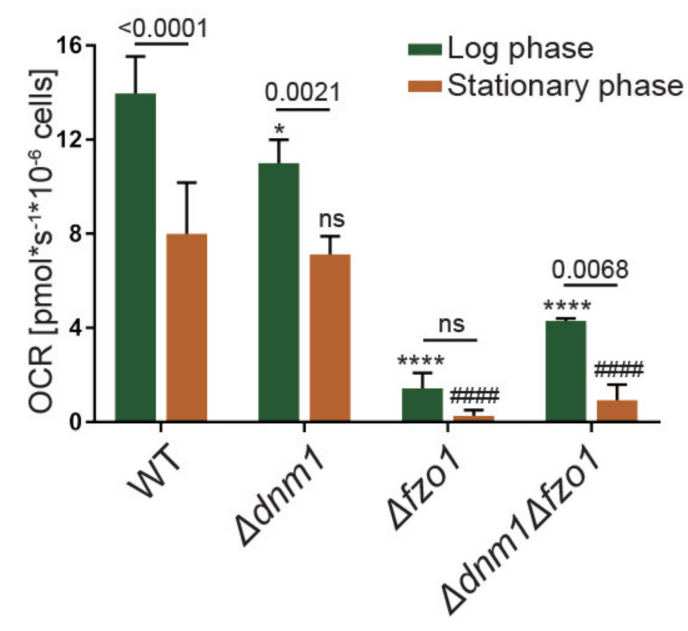

(b) Spare Respiratory Capacity

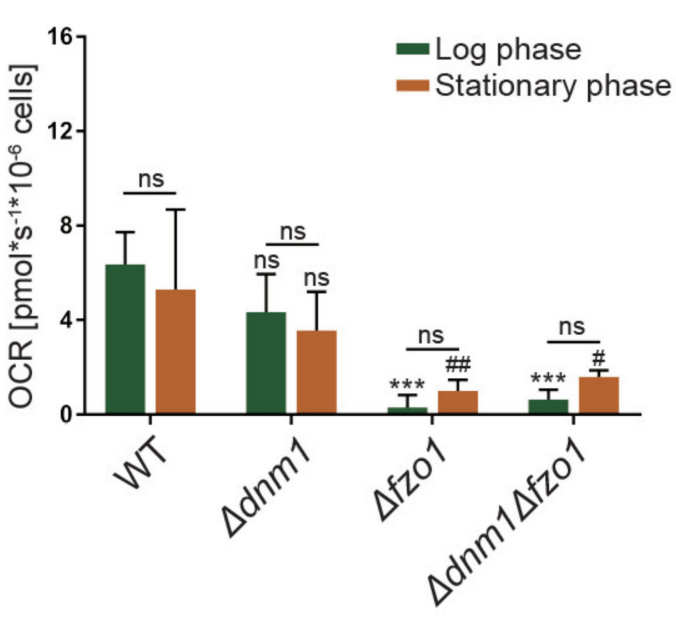

Figure 5. Mitochondrial respiration in wild type and mutant cells. The oxygen consumption rate of different yeast strains was measured in both log (green) and stationary growth phases (orange). Two-way ANOVA multiple comparison was used for statistics analysis. The individual growth phase comparison was calculated based on mutant strain to wild type strain and marked with either * or \#. The $p$ value of individual strain for different growth phase was depicted in the figure. (a) Routine respiration of different strains. (b) Spare respiratory capacity based on the results of coupling control protocol.

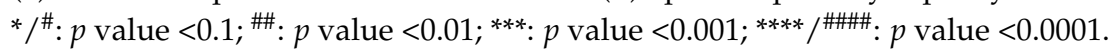




\section{Discussion}

Yeast cells have a remarkable ability to survive the loss of almost all water and recover from dehydrated status. Previous studies have emphasized the importance of stationary phase in the resistance to dehydration [35]. Our results demonstrated one step further that maintaining the ability to adjust mitochondrial dynamics in stationary growth phase is critical for desiccation tolerance. Although we have not characterized what make wild type cells more resistant to dehydration, our results demonstrate that defects in adjusting mitochondrial dynamics caused a significantly lower survival rate after dehydration/rehydration. Dynamic fusion and fission defects caused a loss of mitochondrial genome and activity. Our results suggest that utilizing dynamic processes in stationary phase, which helps preserving mitochondrial genome and maintaining respiration activity, is critical for a cell's resistance to dehydration (Figure 6 and Supplemental Figure S2).

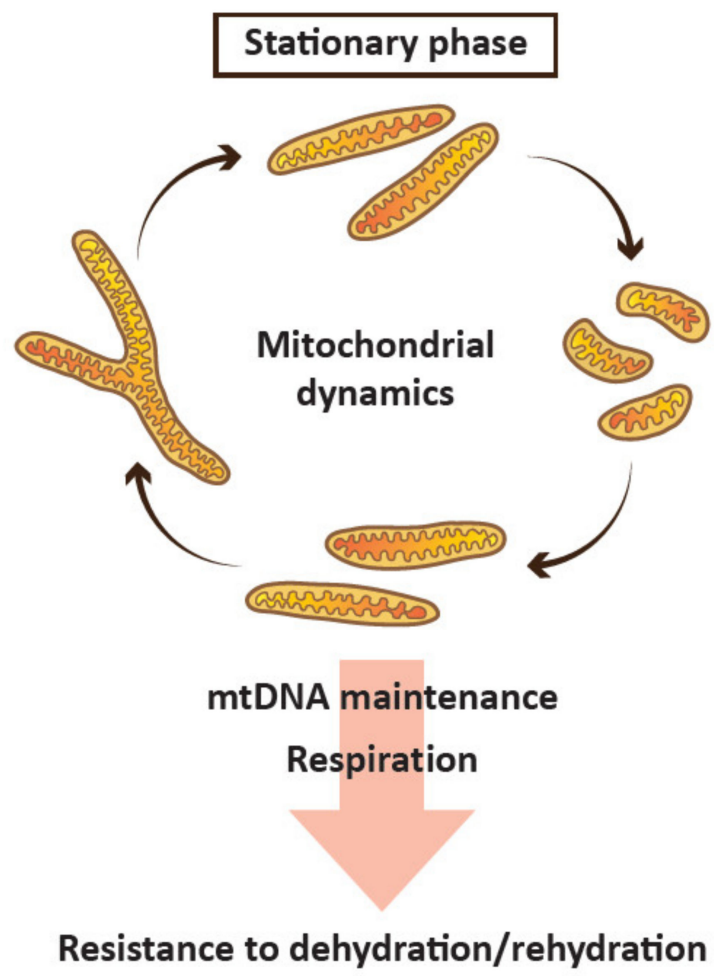

Figure 6. Dynamic fusion and fission aid dehydration resistance by preserving mitochondrial genome in stationary growth phase. Schematic showing that fusion and fission in stationary phase facilitate to preserve mitochondria, especially by maintaining mtDNA. The dynamic processes facilitate the dehydration resistance of yeast cells.

\subsection{Mitochondrial Dynamics Changes along with Growth and Nutrition Supply Conditions}

Wild type yeast cells typically contain tubular mitochondria in exponential growth phase. Our results demonstrated mitochondrial network turned into fragmented during the stationary growth phase. The change in the balance of mitochondrial dynamics may be due to the alteration of nutrition condition in the medium. We suspect that the critical component is dextrose because yeast cells adjusting their metabolism depend on a carbon source [36]. Mechanisms that regulate mitochondrial morphogenesis and mitochondrial functions are varied under different specific extrinsic or intrinsic metabolic cues [16]. Our results showed that mitochondrial dynamics in stationary growth phase is beneficial for desiccation tolerance in yeast, and several reports also suggest fragmented mitochondria are more stress-resistant $[37,38]$. However, the signaling pathways responsible for the change of mitochondrial dynamics in the stationary phase remain to be elucidated. 


\subsection{Disrupted Fusion and Fission Balance Is Associated with mtDNA Loss and Lower Desiccation Tolerance}

Being able to adjust mitochondrial dynamics is critical for cells while encountering environmental stress. In WT cells, fragmented mitochondria phenotype in stationary phase correlates with dehydration resistance. In contrast, the presence of more fragmented mitochondria in $\Delta f z o 1$ cells correlates with less resistance to dehydration (Figure 3). This result demonstrated that a well-maintained mitochondrial dynamics machinery contributes to dehydration resistance. Among the factors that influence mitochondrial dynamics, mtDNA copy number appears to be a potential indicator of resistance to dehydration, as more mtDNA in stationary phase and in wild type cells compared to $\Delta d n m 1, \Delta f z o 1$ and $\Delta d n m 1 \Delta f z o 1$ mutants leads to better resistance to dehydration. We suspect that cells with a higher mtDNA copy number have a larger reservoir of mitochondria genome to consume while encountering harsh dehydration/rehydration environmental stress (Figures 4 and 5). The results of double deletion strain $\Delta d n m 1 \Delta f z o 1$ with slightly higher mtDNA copy number along with a higher survival rate after dehydration/rehydration supported our speculation about mtDNA copy number in dehydration resistance. The mitochondrial network morphology of $\Delta d n m 1 \Delta f z o 1$ cells in a stationary phase was not like $\Delta d n m 1$ or $\Delta f z o 1$ single deletion strains (Figure 3). The $\Delta d n m 1 \Delta f z o 1$ double deletion strains morphology in a stationary phase is like that in wild type cells. This result not only implied that a minor fusion/fission machinery exists, but that dynamic process per se is critical for resistance to dehydration. The uncharacterized fusion/fission machineries revealed their function only when the conventional fusion/fission was completely blocked.

\subsection{Desiccation Tolerance Relies on Well-Regulated Mitochondrial Dynamics to Maintain Organellar Integrity and Signaling}

Researches have shown that mitochondrial fission facilitates mitochondrial inheritance [39] and elimination of dysfunctional mitochondria [40,41]. Studies from Osman et al. indicated that fusion and fission defects cause loss of mtDNA integrity with structural variations [42]. Our results support this notion. Deletion of dynamics factors caused reduced mtDNA copy number and respiration capacity in both log and stationary growth phases (Figure 5). The attenuated mitochondria eventually caused compromised dehydration resistance. A notable result is that mtDNA copy number is generally higher in stationary cells than log phase cells. We suspect this may be related to the compensation of mitochondria under stationary stress. Thus, additional factors involved in maintaining mitochondria integrity and dehydration resistance remain to be characterized.

In summary, we found that mitochondrial dynamics machinery contributes to desiccation tolerance in yeast cells by maintaining mitochondria integrity. Preservation of yeast strains, plant seeds and other organisms frequently involves dehydration of cells. Our results suggest that better survival rate after dehydration/rehydration processes requires a better approach to maintain the organelle's integrity.

\section{Materials and Methods}

\subsection{Yeast Strain Constructions and Growth Conditions}

We used Saccharomyces cerevisiae W303-1a as the parental wild type strain in this study to construct deletion strains. All the strains used in this study are listed in Supplemental Table S1. W303-1a isogenic deletion mutants were generated by direct PCR replacement with either auxotrophic (histidine, HIS3MX6) or antibiotic (hygromycin B phosphotransferase, HPHMX6) cassettes. Mitochondrial genome depletion strain $r h 0^{0}$ were generated by ethidium bromide treatment [43] and selected by non-fermentable carbon source medium. Liquid YPD (1\% Yeast extract, 2\% Bacto-Peptone, 2\% Dextrose) and synthetic complete medium were prepared for yeast cultures at $30^{\circ} \mathrm{C}$ in this study.

\subsection{Desiccation and Rehydration}

Desiccation protocol is as Figure 1 [28]. In short, fresh yeast colonies were picked from YPD agar plate ( $2 \%$ agarose) and culture in $200 \mathrm{~mL}$ liquid $\mathrm{YPD}$ at $30^{\circ} \mathrm{C}, 220 \mathrm{rpm}$. 
Freshy yeast inoculum took about $44-48 \mathrm{~h}$ to grow to stationary phase. Yeast cells were then centrifuged and washed with PBS (Phosphate Buffered Saline 1x; pH 7.0). A small volume of PBS $(1 \times ; \mathrm{pH} 7.0$; about $15-20 \mathrm{~mL})$ was added to resuspend yeast cells. Equal biomass in individual Eppendorf was aliquoted based on spectrophotometry (O.D. 600). Cells were centrifuged again to discard supernatant. Pellets were dried in incubator at $30{ }^{\circ} \mathrm{C}$ for $24 \mathrm{~h}$ or till pellets could be easily moved. Water content of pellets was measured by calculating remnant water weight in microfuge tubes. Based on the weighting, each patch of dehydrated yeast cells contained $6-10 \%$ water content at this state compared to those cells without incubation. Rehydration solution was either YPD or $1 \times$ PBS depended on the experiments described.

\subsection{Cell Viability Assay}

Spot Assay: Yeast cells were cultured and dehydrated as described previously. Samples were taken as shown in Figure 1 and serial ten-fold dilutions were done in a 96-well plate. All dilutions were spotted by multi-blot replicator VP407AH on YPD agar plate incubating at $30^{\circ} \mathrm{C}$ for 2 days before taking images.

Methylene Blue Staining: Yeast cells were cultured and dehydrated as described previously. Dry yeasts were rehydrated with YPD for $20 \mathrm{~min}$ to revive cells. These rehydrated cells were centrifuged and resuspended with methylene blue $\left(0.1 \mathrm{mg} \cdot \mathrm{mL}^{-1}\right.$ stock solution, dissolved in PBS solution) for $15 \mathrm{~min}$. Cell viability ratio was measured by counting above 500 cells in each strain [44].

\subsection{Microscopy}

The Axioskop 2 mot plus fluorescence microscope (Carl Zeiss, Oberkochen, Germany) along with camera system was under Zeiss Zen software control. Live cells samples were cultured to experimental phase for imaging. To visualize mitochondria under fluorescent microscope, we transformed two micron-based plasmid pVT100U-mtGFP to overexpress GFP fused with Su9(1-69) targeting to mitochondrial matrix [45]. Images were analyzed by either Axiovision 4.6 or Zen 2012 version.

\subsection{Quantitative PCR for $m t D N A$}

DNA extraction was carried out by traditional phenol-chloroform approach. Quantitative PCR (qPCR) was conducted using SensiFAST ${ }^{\mathrm{TM}} \mathrm{SYBR}^{\circledR}$ Hi-ROX Kit (Bioline) followed by protocol provided by Bioline (https:/ / www.bioline.com/sensifast-sybr-hi-rox-kit.html (accessed on 26 April 2021)). The amplified sequences are 21S rRNA on mtDNA and SCR1 on chromosome $\mathrm{V}$ in yeast nuclear genome. We quantify the amount of mtDNA copy number per nuclear genome with following primers: mtDNA forward primer: $5^{\prime}-$ CCGTAATGTAGACCGACTCAG-3' ${ }^{\prime}$, mtDNA reverse primer: 5'-TGGAGCAGAGTTCA CACCTTA- ${ }^{\prime}$, nuclear DNA forward primer: $5^{\prime}$-CGCGGCTAGACACGGATT-3' , nuclear DNA reverse primer: $5^{\prime}$-GCACGGTGCGGAATAGAGAA-3'. Data of qPCR were analyzed by comparing threshold cycles with $\triangle \triangle \mathrm{C}(\mathrm{t})$ by StepOnePlus Detection System (Applied Biosystems, Foster, CA, USA).

\subsection{High Resolution Respirometry}

Yeast mitochondrial oxygen consumption was measured at $30^{\circ} \mathrm{C}$ by high resolution Oxygraph-2k (OROBOROS Instruments, Innsbruck, Austria). We used culture medium as assay buffer and respiration complexes inhibitors based on coupling control protocol to measure mitochondrial respiration [33]. Yeast cells were placed in a $2 \mathrm{~mL}$ chamber at a final concentration of $5 \times 10^{6}$ cells $/ \mathrm{mL}$. After basal respiration was recorded, Triethyltin (TET, $150 \mu \mathrm{M})$, Carbonyl cyanide p-trifluoromethoxy phenylhydrazone (FCCP, 3, 5, $7 \mu \mathrm{M}$ ), and Antimycin $\mathrm{A}(2 \mu \mathrm{M})$ were used for measuring respiration at leak state, proton gradient uncoupled state, and electron transport chain blocking state, respectively. Inhibitors injection protocol was modified by the previous study [34]. Oxygen consumption rate, OCR, (in pmol $/ \mathrm{s} \times 10^{6}$ cells) is directly proportional to oxygen consumption, which is 
calculated by the decrease slope of oxygen concentration. Data were continuously recorded and analyzed by DatLab 6 software.

\subsection{Statistical Analysis}

All experimental results shown here are the results of three biological replicates. To classify fragmented mitochondria, $>200$ cells were examined in each trail. Statistical analysis was performed using GraphPad Prism 7 (GraphPad Software, California USA). Histograms present the mean; error bars represent the standard deviation. Specified methods were used to calculate $p$ value as mentioned in the figure legends. Statistical

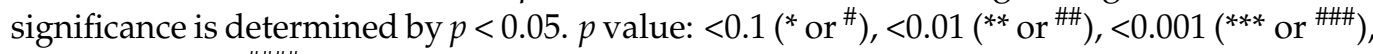

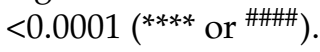

Supplementary Materials: The following are available online at https:/ /www.mdpi.com/article/10 $.3390 /$ ijms $22094607 / \mathrm{s} 1$.

Author Contributions: Conceptualization, C.-L.C., S.L., R.D., A.R. and C.-R.C.; methodology, C.-L.C., S.L., A.R. and C.-R.C.; investigation, C.-L.C., Y.-C.C. and W.-L.H.; resources, R.D., A.R. and C.-R.C.; data curation, C.-L.C., W.-L.H. and C.-R.C.; writing-C.-L.C.; writing-review and editing, S.L., A.R. and C.-R.C.; visualization, C.-L.C., W.-L.H. and C.-R.C.; supervision, C.-R.C.; funding acquisition, R.D., A.R. and C.-R.C. All authors have read and agreed to the published version of the manuscript.

Funding: This research was funded by the Ministry of Science and Technology of Taiwan (105-2923B-007-001-MY3, 108-2320-B-007-002- and 109-2320-B-007-004-) and Academia Sinica (AS-TP-L107-1).

Institutional Review Board Statement: Not applicable.

Informed Consent Statement: Not applicable.

Data Availability Statement: The data that support the findings of this study are available from the corresponding author upon reasonable request.

Acknowledgments: We thank the staff of the Taiwan Yeast Bioresource Center at the First Core Labs National Taiwan University College of Medicine, for bioresources sharing. We would also like to thank Wei Yuan Yang at Academia Sinica for his critical comments about the manuscript.

Conflicts of Interest: The authors declare no conflict of interest.

\section{References}

1. Rapoport, A.; Golovina, E.A.; Gervais, P.; Dupont, S.; Beney, L. Anhydrobiosis: Inside yeast cells. Biotechnol. Adv. 2019, 37, 51-67. [CrossRef]

2. Rapoport, A. Anhydrobiosis and Dehydration of Yeasts. In Biotechnology of Yeasts and Filamentous Fungi; Sibirny, A.A., Ed.; Springer International Publishing: Cham, Switzerland, 2017; pp. 87-116.

3. Rapoport, A.; Turchetti, B.; Buzzini, P. Application of anhydrobiosis and dehydration of yeasts for non-conventional biotechnological goals. World J. Microb. Biot. 2016, 32. [CrossRef]

4. Tapia, H.; Young, L.; Fox, D.; Bertozzi, C.R.; Koshland, D. Increasing intracellular trehalose is sufficient to confer desiccation tolerance to Saccharomyces cerevisiae. Proc. Natl. Acad. Sci. USA 2015, 112, 6122-6127. [CrossRef] [PubMed]

5. Tapia, H.; Koshland, D.E. Trehalose is a versatile and long-lived chaperone for desiccation tolerance. Curr. Biol. 2014, 24, 2758-2766. [CrossRef] [PubMed]

6. Dupont, S.; Rapoport, A.; Gervais, P.; Beney, L. Survival kit of Saccharomyces cerevisiae for anhydrobiosis. Appl. Microbiol. Biotechnol. 2014, 98, 8821-8834. [CrossRef] [PubMed]

7. Lopez-Martinez, G.; Rodriguez-Porrata, B.; Margalef-Catala, M.; Cordero-Otero, R. The STF2p hydrophilin from Saccharomyces cerevisiae is required for dehydration stress tolerance. PLoS ONE 2012, 7, e33324. [CrossRef] [PubMed]

8. Khroustalyova, G.; Rapoport, A. Anhydrobiosis in Yeasts: Changes in Mitochondrial Membranes Improve the Resistance of Saccharomyces cerevisiae Cells to Dehydration-Rehydration. Fermentation 2019, 5, 82. [CrossRef]

9. Kuliesiene, N.; Zukiene, R.; Khroustalyova, G.; Chang, C.R.; Rapoport, A.; Daugelavicius, R. Changes in Energy Status of Saccharomyces cerevisiae Cells during Dehydration and Rehydration. Microorganisms 2021, 9, 444. [CrossRef] [PubMed]

10. Capece, A.; Votta, S.; Guaragnella, N.; Zambuto, M.; Romaniello, R.; Romano, P. Comparative study of Saccharomyces cerevisiae wine strains to identify potential marker genes correlated to desiccation stress tolerance. FEMS Yeast Res. 2016, 16. [CrossRef]

11. Picazo, C.; Gamero-Sandemetrio, E.; Orozco, H.; Albertin, W.; Marullo, P.; Matallana, E.; Aranda, A. Mitochondria inheritance is a key factor for tolerance to dehydration in wine yeast production. Lett. Appl. Microbiol. 2015, 60, 217-222. [CrossRef]

12. Koshland, D.; Tapia, H. Desiccation tolerance: An unusual window into stress biology. Mol. Biol. Cell 2019, 30, 737-741. [CrossRef] 
13. Yapa, N.M.B.; Lisnyak, V.; Reljic, B.; Ryan, M.T. Mitochondrial dynamics in health and disease. FEBS Lett. 2021. [CrossRef]

14. Loncke, J.; Kaasik, A.; Bezprozvanny, I.; Parys, J.B.; Kerkhofs, M.; Bultynck, G. Balancing ER-Mitochondrial Ca(2+) Fluxes in Health and Disease. Trends Cell Biol. 2021. [CrossRef]

15. Wanderoy, S.; Hees, J.T.; Klesse, R.; Edlich, F.; Harbauer, A.B. Kill one or kill the many: Interplay between mitophagy and apoptosis. Biol. Chem. 2020, 402, 73-88. [CrossRef]

16. Mishra, P.; Chan, D.C. Metabolic regulation of mitochondrial dynamics. J. Cell Biol. 2016, 212, 379-387. [CrossRef]

17. Calahan, D.; Dunham, M.; DeSevo, C.; Koshland, D.E. Genetic analysis of desiccation tolerance in Sachharomyces cerevisiae. Genetics 2011, 189, 507-519. [CrossRef] [PubMed]

18. Ren, Q.; Brenner, R.; Boothby, T.C.; Zhang, Z. Membrane and lipid metabolism plays an important role in desiccation resistance in the yeast Saccharomyces cerevisiae. BMC Microbiol. 2020, 20, 338. [CrossRef]

19. Ratnakumar, S.; Hesketh, A.; Gkargkas, K.; Wilson, M.; Rash, B.M.; Hayes, A.; Tunnacliffe, A.; Oliver, S.G. Phenomic and transcriptomic analyses reveal that autophagy plays a major role in desiccation tolerance in Saccharomyces cerevisiae. Mol. Biosyst. 2011, 7, 139-149. [CrossRef] [PubMed]

20. Giacomello, M.; Pyakurel, A.; Glytsou, C.; Scorrano, L. The cell biology of mitochondrial membrane dynamics. Nat. Rev. Mol. Cell Biol. 2020, 21, 204-224. [CrossRef]

21. Chen, Y.C.; Cheng, T.H.; Lin, W.L.; Chen, C.L.; Yang, W.Y.; Blackstone, C.; Chang, C.R. Srv2 Is a Pro-fission Factor that Modulates Yeast Mitochondrial Morphology and Respiration by Regulating Actin Assembly. iScience 2019, 11, 305-317. [CrossRef] [PubMed]

22. Moehlman, A.T.; Youle, R.J. Mitochondrial Quality Control and Restraining Innate Immunity. Annu. Rev. Cell Dev. Biol. 2020, 36, 265-289. [CrossRef] [PubMed]

23. Bleazard, W.; McCaffery, J.M.; King, E.J.; Bale, S.; Mozdy, A.; Tieu, Q.; Nunnari, J.; Shaw, J.M. The dynamin-related GTPase Dnm1 regulates mitochondrial fission in yeast. Nat. Cell Biol. 1999, 1, 298-304. [CrossRef] [PubMed]

24. Tamura, Y.; Itoh, K.; Sesaki, H. SnapShot: Mitochondrial dynamics. Cell 2011, 145, 1158-1158.e1. [CrossRef]

25. Blackstone, C.; Chang, C.R. Mitochondria unite to survive. Nat. Cell Biol. 2011, 13, 521-522. [CrossRef]

26. Chang, C.R.; Blackstone, C. Dynamic regulation of mitochondrial fission through modification of the dynamin-related protein Drp1. Ann. N. Y. Acad. Sci. 2010, 1201, 34-39. [CrossRef] [PubMed]

27. Abrisch, R.G.; Gumbin, S.C.; Wisniewski, B.T.; Lackner, L.L.; Voeltz, G.K. Fission and fusion machineries converge at ER contact sites to regulate mitochondrial morphology. J. Cell Biol. 2020, 219. [CrossRef] [PubMed]

28. Borovikova, D.; Teparic, R.; Mrsa, V.; Rapoport, A. Anhydrobiosis in yeast: Cell wall mannoproteins are important for yeast Saccharomyces cerevisiae resistance to dehydration. Yeast 2016, 33, 347-353. [CrossRef]

29. Narendra, D.P.; Jin, S.M.; Tanaka, A.; Suen, D.F.; Gautier, C.A.; Shen, J.; Cookson, M.R.; Youle, R.J. PINK1 is selectively stabilized on impaired mitochondria to activate Parkin. PLoS Biol. 2010, 8, e1000298. [CrossRef]

30. Kondadi, A.K.; Anand, R.; Reichert, A.S. Functional Interplay between Cristae Biogenesis, Mitochondrial Dynamics and Mitochondrial DNA Integrity. Int. J. Mol. Sci. 2019, 20, 4311. [CrossRef]

31. Chen, H.; Vermulst, M.; Wang, Y.E.; Chomyn, A.; Prolla, T.A.; McCaffery, J.M.; Chan, D.C. Mitochondrial fusion is required for mtDNA stability in skeletal muscle and tolerance of mtDNA mutations. Cell 2010, 141, 280-289. [CrossRef]

32. Miyakawa, I. Organization and dynamics of yeast mitochondrial nucleoids. Proc. Jpn. Acad. Ser. B Phys. Biol. Sci. 2017, 93, 339-359. [CrossRef]

33. Pesta, D.; Gnaiger, E. High-resolution respirometry: OXPHOS protocols for human cells and permeabilized fibers from small biopsies of human muscle. Methods Mol. Biol. 2012, 810, 25-58.

34. Leadsham, J.E.; Gourlay, C.W. cAMP/PKA signaling balances respiratory activity with mitochondria dependent apoptosis via transcriptional regulation. BMC Cell Biol. 2010, 11, 92. [CrossRef]

35. Zambuto, M.; Romaniello, R.; Guaragnella, N.; Romano, P.; Votta, S.; Capece, A. Identification by phenotypic and genetic approaches of an indigenous Saccharomyces cerevisiae wine strain with high desiccation tolerance. Yeast 2017, 34, 417-426. [CrossRef]

36. Weinhandl, K.; Winkler, M.; Glieder, A.; Camattari, A. Carbon source dependent promoters in yeasts. Microb. Cell Fact. 2014, 13, 5. [CrossRef]

37. Kitagaki, H.; Araki, Y.; Funato, K.; Shimoi, H. Ethanol-induced death in yeast exhibits features of apoptosis mediated by mitochondrial fission pathway. FEBS Lett. 2007, 581, 2935-2942. [CrossRef]

38. Knorre, D.A.; Ojovan, S.M.; Saprunova, V.B.; Sokolov, S.S.; Bakeeva, L.E.; Severin, F.F. Mitochondrial matrix fragmentation as a protection mechanism of yeast Saccharomyces cerevisiae. Biochemistry 2008, 73, 1254-1259. [CrossRef]

39. Klecker, T.; Scholz, D.; Förtsch, J.; Westermann, B. The yeast cell cortical protein Num1 integrates mitochondrial dynamics into cellular architecture. J. Cell Sci. 2013, 126, 2924. [CrossRef]

40. Mao, K.; Wang, K.; Liu, X.; Klionsky, D.J. The Scaffold Protein Atg11 Recruits Fission Machinery to Drive Selective Mitochondria Degradation by Autophagy. Dev. Cell 2013, 26, 9-18. [CrossRef]

41. Abeliovich, H.; Zarei, M.; Rigbolt, K.T.G.; Youle, R.J.; Dengjel, J. Involvement of mitochondrial dynamics in the segregation of mitochondrial matrix proteins during stationary phase mitophagy. Nat. Commun. 2013, 4, 2789. [CrossRef]

42. Osman, C.; Noriega, T.R.; Okreglak, V.; Fung, J.C.; Walter, P. Integrity of the yeast mitochondrial genome, but not its distribution and inheritance, relies on mitochondrial fission and fusion. Proc. Natl. Acad. Sci. USA 2015, 112, E947-E956. [CrossRef]

43. Goldring, E.S.; Grossman, L.I.; Marmur, J. Petite Mutation in Yeast. J. Bacteriol. 1971, 107, 377-381. [CrossRef] [PubMed] 
44. Kwolek-Mirek, M.; Zadrag-Tecza, R. Comparison of methods used for assessing the viability and vitality of yeast cells. FEMS Yeast Res. 2014, 14, 1068-1079. [CrossRef] [PubMed]

45. Westermann, B.; Neupert, W. Mitochondria-targeted green fluorescent proteins: Convenient tools for the study of organelle biogenesis in Saccharomyces cerevisiae. Yeast 2000, 16, 1421-1427. [CrossRef] 